\title{
PERBEDAAN PENGARUH MODEL PEMBELAJARAN COOPERATIVE SCRIPT BERBANTUAN PETA PIKIRAN DENGAN DIRECT INSTRUCTION TERHADAP HASIL BELAJAR SISWA PADA POKOK BAHASAN PROGRAM LINEAR
}

\author{
Nur Rohman \\ Program Studi Pendidikan Matematika, IKIP PGRI Bojonegoro \\ e-mail: nurrohmanspd83@yahoo.co.id
}

\begin{abstract}
The objectives of this research are to investigate whether there is difference of influence student learning result after application of cooperative script learning model assisted mind map with direct instruction learning model on the subject of Program Linear class X of SMA Plus Al-Amanah Balongsumber Dander Bojonegoro in the academic year of 2014/2015. This study is a quasi-experimental study using a study design of post-test - only control design. The sampling technique using cluster random sampling technique. The sample in this research is class X-B as an experimental class and class X-C as the control class. Data mathematics learning result obtained using the technique of tests, and the tests used in the form of an objective test. Data were analyzed by an independent comparative statistical t-test. Based on the research results, it was concluded that: there is a significant difference between students' mathematics learning result that learned through the cooperative scriptlearning model assisted mind map with the students that learned through direct instruction learning. This suggests there are differences in the effect of the cooperative script learning model assisted mind map with direct learning model mathematics instruction on learning result of students on the subject of Program Linear second semester of class X SMA Plus Al-Amanah Bojonegoro.
\end{abstract}

Key Words: Cooperative Script Assisted Mind Map, Direct Instruction, Learning Result.

\begin{abstract}
Abstrak: Tujuan dari penelitian ini adalah untuk menginvestigasi ada tidaknya perbedaan pengaruh terhadap siswa yang belajar menggunakan model pembelajaran naskah cooperative yang didampingi dengan "Mind Map" dengan model pembelajaran instruksi langsung pada materi Program Linear untuk kelas X dari SMA Pluss Al-Amanah Balongsumber Dander Bojonegoro Tahun Akademik 2014/2015. Jenis penelitian ini adalah eksperimen semu yang menggunakan desain post test control. Teknik pengambilan sample menggunakan cluster random sampling. Sampel yang digunakan adalah kelas X-B sebagai kelas eksperimen dan kelas X-C sebagai kelas kontrol. Data penelitian diperoleh melalui teknik tes, yaitu dalam bentuk tes objektif. Berdasarkan hasil penelitian, dapat disimpulkan bahwa: terdapat perbedaan yang besar antara siswa yang belajar matematika menggunakan metode pembelajaran naskah kooperatif dengan didampingi "mind Map" dengan siswa yang belajar matematika menggunakan metode instruksi langsung. Hal ini membuktikan bahwa adanya perbedaan efek dari pembelajaran naskah kooperatif dengan didampingi "Mind Map" dengan pembelajaran instruksi langsung yang ditunjukkan oleh hasil belajar siswa pada materi problem Linear.
\end{abstract}

Kata Kunci: Cooperative Script Assisted Mind Map, Instruksi Langsung, Hasil Belajar

\section{PENDAHULUAN}

Menurut kurikulum KTSP 2006 pembelajaran matematika dituntut berorientasi pada pembelajaran proses, artinya peserta didik harus aktif terlibat dalam proses memperoleh produk. Hal ini berarti selama 
mengikuti proses belajar mengajar peserta didik tidak diperbolehkan pasif atau menerima informasi dari guru saja, tetapi harus bekerja memecahkan masalah, memahami dan menerapkan pengetahuan serta konsepnya sendiri (Slavin dalam Cahyaning, 2004: 8).

Matematika merupakan salah satu bidang studi yang menduduki peranan penting dalam pendidikan. Hal ini dapat dilihat dari waktu jam pelajaran sekolah lebih banyak dibandingkan pelajaran lain. Meskipun demikian, hasil belajar siswa dalam bidang matematika relatif rendah bila dibandingkan dengan pelajaran yang lain. Hal ini dapat dilihat dari nilai rata-rata Ujian Akhir Sekolah SMA Plus Al-Amanah Balongsumber Dander Bojonegoro Tahun Pelajaran 2014/ 2015. Bahasa Indonesia 7,50; Bahasa Inggris 7,90; Matematika 7,24; dan Ilmu Pengetahuan Alam 8,25. Hal ini menunjukkan perlu adanya pembenahan dari berbagai komponen yang terkait dengan pembelajaran matematika.

Pendidikan matematika menyangkut proses, belajar mengajar, dan pemikiran kreatif. Kesulitan yang dialami siswa dalam mata pelajaran itu terdapat beberapa faktor yang mempengaruhinya. Menurut Syah (2007: 144) bahwa, faktor-faktor yang mempengaruhi hasil belajar siswa dapat dibedakan menjadi tiga macam, yakni: 1) faktor internal (faktor dari dalam siswa), yakni keadaan/kondisi jasmani dan rohani siswa yang meliputi aspek fisiologis (yang bersifat jasmaniah), aspek psikologis (yang bersifat rohaniah), 2) faktor eksternal (faktor dari luar siswa), yakni kondisi lingkungan di sekitar siswa yang meliputi faktor lingkungan sosial dan faktor lingkungan non sosial, 3) faktor pendekatan belajar (approach tolearning), yakni jenis upaya belajar siswa yang meli-puti strategi dan metode yang digunakan siswa untuk melakukan kegiatan mempelajari materi-materi pelajaran yang meliputi pendekatan tinggi (speculative dan achieving), pendekatan menengah (analitical dan deep), dan pendekatan rendah (reproductive dan surface).

Suatu kegiatan yang tidak terpisahkan dari proses pembelajaran adalah kegiatan mengajar. Menurut Sardiman (dalam Nuha, 2013) mengajar adalah usaha untuk menciptakan kondisi yang kondusif agar berlangsung kegiatan belajar yang bermakna dan optimal, sehingga dapat mengoptimalisasikan kegiatan belajar dengan hasil yang bermakna. Sehingga dalam implementasinya guru harus selalu berupaya untuk mencari dan menemukan berbagai strategi pembelajaran yang dapat memperkaya pengalaman belajar anak melalui serangkaian kegiatan yang dapat mengeksplorasi lingkungan melalui interaksi aktif terhadap lingkungan fisik maupun sosialnya.

Akan tetapi hal itu tidaklah mudah karena komposisi siswa dalam kelas pada sekolah-sekolah umumnya terdiri dari siswa yang memiliki tingkat kecerdasan yang bervariasi baik dalam hal kecerdasan intelektual, kecerdasan verbal, kecerdasan visual maupun kecerdasan interpersonal.

Kondisi ini menyebabkan siswa yang tingkat kecerdasan intelektualnya kurang cenderung bersifat pasif (kurang interaktif), bersikap acuh (kurang partisipatif), dan merasa rendah diri karena tidak mampu berperan. Pada akhirnya mereka malas dan melakukan hal-hal yang tidak ada kaitannya dengan pelajaran. Pembelajaran merupakan suatu proses kerjasama, tidak hanya menitikberatkan pada kegiatan guru atau kegiatan siswa saja, akan tetapi guru dan siswa secara bersama-sama berusaha mencapai tujuan pembelajaran yang telah ditentukan. Siswa adalah subyek utama dalam belajar. Siswa harus mempunyai motivasi, kritis dan kreatif dalam pembelajaran matematika, sehingga pembelajaran berlangsung 
secara efektif.

Salah satu faktor rendahnya hasil belajar matematika mungkin berasal dari faktor kualitas pembelajaran guru dalam menyampaikan materi pelajaran kurang menarik. Masih banyak guru dalam mengajar menggunakan model pembelajaran langsung yaitu pembelajaran yang berpusat pada guru. Dalam model ini lebih banyak menuntut keaktifan guru dari pada siswa sebagai peserta didik sehingga siswa kurang aktif dalam proses belajar mengajar.

Salah satu alternatif model pembelajaran yang dapat diterapkan dalam proses pembelajaran adalah model pembelajaran kooperatif. Davidson dan Warsham (Isjoni, 2011: 27) pembelajaran kooperatif adalah kegiatan belajar mengajar secara kelompok -kelompok kecil, siswa belajar dan bekerjasama untuk sampai kepada pengalaman belajar yang berkelompok pengalaman individu maupun pengalaman kelompok.

Metode pengajaran yang bervariasi merupakan salah satu upaya agar siswa selalu menunjukkan ketekunan, perhatian, keantusiasan, motivasi yang tinggi dan kesediaan berperan serta secara aktif. Pada dasarnya siswa satu berbeda dengan siswa yang lainnya. Karena perbedaan ini diperlukan sebuah alternatif pembelajaran yang memungkinkan terpenuhinya kemampuan individual siswa. Oleh karena itu peneliti menggunakan metode yang belum pernah diterapkan di SMA Plus Al-Amanah Balongsumber Dander Bojonegoro yaitu metode pembelajaran Cooperative Script dengan berbantuan peta pikiran.

Sohimin (2004) menyatakan bahwa, model Cooperative Script dipilih karena bisa mengajak siswa lebih berfikir kreatif serta lebih tinggi ingatan siswa. Siswa juga diberi kesempatan untuk lebih aktif, saling bekerjasama dan menjadikan siswa lebih berani mengemukakan pendapatnya. Hal ini disebabkan karena model pembelajaran Cooperative Script dalam proses pembelajarannya siswa belajar secara berpasangpasangan dan berani untuk mempresentasikan jawabannya. Demikian pula berdasarkan hasil penelitian yang dilakukan oleh Muniroh (2010) menyatakan bahwa model pembelajaran Cooperative Script dapat meningkatkan daya ingat dan kreativitas siswa dari $63,33 \%$ menjadi $75 \%$. Daya ingat siswa sangat diperlukan untuk memunculkan kreativitas dalam pemecahan masalah, karena kreativitas merupakan kemampuan untuk membuat kombinasi baru berdasarkan data atau informasi yang telah dikenal sebelumnya.

Sani (2013) menyatakan bahwa, peta pikiran merupakan salah satu bentuk pembelajaran yang digunakan untuk melatih kemampuan penyajian isi (content) materi dengan pemetaan pikiran. Peta pikiran dapat membantu siswa berpikir secara kreatif sekaligus kritis, mengingat dengan baik pelajaran, memahami isi bacaan, dan penugasan lain yang diberikan serta membantu siswa mempersiapkan presentasi dengan cara mengembangkan ide-ide pemikirannya.

Berdasarkan pemaparan di atas, masalah yang akan dikaji dalam penelitian ini adalah "Apakah ada perbedaan pengaruh model pembelajaran Cooperative Script berbantuan peta pikiran dengan model pembelajaran Direct Instruction terhadap hasil belajar matematika siswa pada pokok bahasan Program Linear?".

Terkait dengan masalah itu, maka tujuan dari penelitian ini adalah untuk mengetahui apakah ada perbedaan pengaruh model pembelajaran Cooperative Script berbantuan peta pikiran dengan model pembelajaran Direct Instruction terhadap hasil belajar matematika siswa pada pokok bahasan Program Linear pada sub pokok bahasan pertidaksamaan linear. 


\section{METODE PENELITIAN}

Penelitian ini merupakan penelitian eksperimental semu (quasi-experimental research). Budiyono (2003: 82) menyatakan bahwa tujuan penelitian eksperimental semu adalah untuk memperoleh informasi yang merupakan perkiraan bagi informasi yang dapat diperoleh dengan eksperimen yang sebenarnya dalam keadaan yang tidak memungkinkan untuk mengontrol atau memanipulasi semua variabel yang relevan.

Menurut Sugiyono (2007: 61), Populasi adalah wilayah generalisai yang terdiri atas: obyek/subyek yang mempunyai kualitas dan karakteristik tertentu yang ditetapkan oleh peneliti untuk dipelajari dan kemudian ditarik kesimpulannya. Populasi dalam penelitian ini adalah seluruh siswa SMA Plus Al-Amanah Balongsumber Bojonegoro kelas X semester II tahun pelajaran 2014/2015 yang terdiri atas tiga kelas yaitu kelas $\mathrm{X}-\mathrm{A}$, $\mathrm{X}-\mathrm{B}$, dan X-C sebanyak 75 siswa. Teknik pengambilan sampel yang digunakan adalah teknik cluster random sampling. Dari tiga kelas yang ada, dipilih dua kelas dengan kemampuan siswa yang seimbang yaitu kelas X-B sebagai kelas eksperimen yang terdiri dari 25 siswa dan kelas $\mathrm{X}-\mathrm{C}$ sebagai kelas kontrol yang terdiri dari 20 siswa.

Instrumen tes dalam penelitian ini adalah hasil belajar matematika pada pokok bahasan Program Linear. Teknik analisis data dalam penelitian ini adalah teknik statistik dengan uji- $t$ komparatif independen yaitu dengan menggunakan rumus Polled Varians (Sugiyono, 2007:138). Uji prasyarat yang dipakai dalam analisis data penelitian adalah uji normalitas dengan metode Lilliefors dan uji homogenitas dengan metode Bartleet.

\section{HASIL DAN PEMBAHASAN}

Nilai hasil belajar dalam pembelajaran dapat dilihat pada Tabel 1 dan 2, sedangkan rangkuman hasil uji- $t$ dapat dilihat pada Tabel 3.

Tabel 1. Distribusi Frekuensi Nilai Post Test Kelas X-B

\begin{tabular}{ccccc}
\hline X-B & $\begin{array}{c}\text { Internal } \\
\text { Nilai }\end{array}$ & Frekuensi & $\begin{array}{c}\text { Nilai } \\
\text { Tengah } \\
(\mathbf{X})\end{array}$ & $\mathbf{f}(\mathbf{X})$ \\
\hline 1 & $64-68$ & 3 & 66 & 198 \\
\hline 2 & $69-73$ & 3 & 71 & 213 \\
\hline 3 & $74-78$ & 4 & 76 & 304 \\
\hline 4 & $79-83$ & 7 & 81 & 567 \\
\hline 5 & $84-88$ & 6 & 86 & 516 \\
\hline 6 & $89-93$ & 2 & 91 & 182 \\
\hline Jumlah & 25 & & 1980 \\
\hline \multicolumn{2}{l}{$\mathbf{S}$} & & & 78.88 \\
\hline
\end{tabular}

Tabel 2. Distribusi Frekuensi Nilai Post Test Kelas X-C

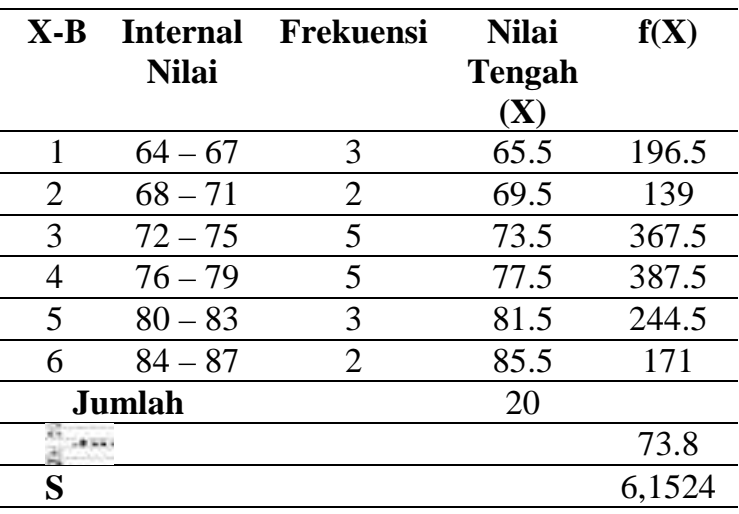

Setelah dilakukan analisis data, dilakukan uji prasyarat analisis. Uji prasyarat analisis meliputi uji normalitas data dan uji homogenitas. Uji normalitas data dapat dilihat pada tabel 3 dibawah ini.

Tabel 3. Hasil Uji Normalitas Post Test

\begin{tabular}{cccc}
\hline Kelas & Lobs & Ltabel & Kesimpulan \\
\hline $\begin{array}{c}\text { Kelas } \\
\text { X-B }\end{array}$ & 0,1209 & 0,1730 & Populasi normal \\
\hline $\begin{array}{c}\text { Kelas } \\
\text { X-C }\end{array}$ & 0,1151 & 0,1900 & Populasi normal \\
\hline
\end{tabular}

Sementara itu, hasil homogenitas data hasil belajar siswa dianalisis dengan uji Barlett. Adapun hasilnya dapat dilihat pada tabel 4 di bawah ini.

Tabel 4. Hasil Uji Homogenitas Post Test

\begin{tabular}{cccc}
\hline Kelas & $\chi_{\text {obs }}^{\mathbf{2}}$ & $\boldsymbol{\chi}^{\mathbf{2}}$ tabel & Kesimpulan \\
\hline $\begin{array}{c}\text { Kelas X-B } \\
\text { dan X-C }\end{array}$ & 0,848 & 3,841 & Variansi Homogen \\
\hline
\end{tabular}


Hasil uji homogenitas menunjukkan bahwa varians homogen dan jumlah siswa pada tiap kelas berbeda, maka pengujian hipotesis ini dilakukan dengan menggunakan analisis uji-t dengan rumus Polled Varians. Hasil uji hipotesis dapat dilihat pada tabel 5 di bawah ini..

Tabel 5. Rangkuman Hasil Uji- $t$ Komparatif Independen

\begin{tabular}{cccc}
\hline Kelompok & $\mathbf{t}_{\text {obs }}$ & $\mathbf{t}_{\text {tabel }}$ & Kesimpulan \\
\hline $\begin{array}{c}\text { Kelas X-B } \\
\text { dan X-C }\end{array}$ & 4,384 & 2,018 & $\mathrm{H}_{0}$ ditolak \\
\hline
\end{tabular}

Dari Tabel 5 diatas diperoleh $\mathrm{H}_{0}$ ditolak, berarti ada perbedaan pengaruh antara model pembelajaran Cooperative Script berbantuan peta pikiran dengan Direct Instruction terhadap hasil belajar siswa pada pokok bahasan Program Linear. Dengan melihat rerata masing-masing kelas, diperoleh kenyataan bahwa siswa-siswa yang diberi model pembelajaran Cooperative Script berbantuan peta pikiran lebih baik hasil belajarnya dibanding dengan siswasiswa yang diberi model pembelajaran Direct Instruction yaitu selisih rata-ratanya sebesar 6,44\%. Hal ini disebabkan dengan model pembelajaran Cooperative Script berbantuan peta pikiran, siswa lebih mudah mengingat pelajaran dan membuat siswa aktif serta kreatif.

\section{SIMPULAN}

Dari hasil penelitian pada analisis data dengan uji ustatistik dan jumlah sampel $=45$ dan taraf signifikansi $\alpha=5 \%$ diperoleh harga perhitungan $\mathrm{t}=4,384$ dan harga t pada tabel $=2,018$. Karena harga t dari perhitungan lebih besar dari harga $t$ pada tabel sehingga $H_{0}$ ditolak berarti $H_{1}$ diterima. Jadi dengan demikian dapat disimpulkan bahwa pada penelitian ini "Ada perbedaan pengaruh model pembelajaran Cooperative Script berbantuan peta pikiran dengan model pembelajaran Direct Instruction terhadap hasil belajar siswa pada siswa kelas X semester 2 SMA Plus Al-Amanah Balongsumber Bojonegoro untuk pokok bahasan Program Linear". Hasil kemampuan siswa dalam penguasaan pokok Program Linear dapat dikatakan optimal apabila siswa tersebut mencapai nilai KKM (Kriteria ketuntasan minimal) yaitu yang ditentukan oleh guru pada mata pelajaran matematika yaitu 70. Berdasarkan nilai yang diperoleh dari ulangan harian Matematika pada pokok bahasan Program Linier tahun sebelumnya yang rata-ratanya 60,33. Sedangkan setelah dilaksanakan pengujian post test dengan perlakuan pada kelompok kelas eksperimen dengan model pembelajaran Cooperative Script berbantuan peta pikiran diperoleh rata-rata 78,88 lebih baik dari siswa yang diberi model pembelajaran Direct Instruction yaitu 73,8. Sehingga dapat disampaikan bahwa model pembelajaran Cooperative Script berbantuan peta pikiran terhadap hasil belajar siswa dalam pokok bahasan Program Linear pada siswa Kelas $X$ SMA Plus Al-Amanah Balongsumber Bojonegoro tahun pelajaran 2014/2015 dapat meningkatkan hasil belajar sebesar $6,44 \%$.

Berdasarkan kesimpulan penelitian di atas, dapat disampaikan saran sebagai berikut: 1) Guru perlu terus meningkatkan kreativitas, profesionalisme, dan kompetensinya dalam mendesain suatu pembelajaran serta menguasai ilmu dan teknologi. Guru berusaha mengajak semua siswa untuk berpartisipasi aktif dalam pembelajaran, antara lain dengan menggunakan media dan model pembelajaran yang efektif sehingga pembelajaran dapat berpusat pada siswa dan siswa termotivasi untuk mempelajarinya; 2) Model pembelajaran Cooperative Script berbantuan peta pikiran dapat digunakan sebagai referensi dan evaluasi dalam proses belajar mengajar; 3) Agar pelaksa- 
naan pembelajaran model pembelajaran Cooperative Script berbantuan peta pikiran dapat berjalan lancar sesuai dengan yang diharapkan, sebaiknya guru memberikan penjelasan tentang makna dan manfaat menggunakan pembelajaran ini dan guru perlu melakukan perencanaan kegiatan pembelajaran. Sehingga waktu yang tersedia dalam pembelajaran dapat digunakan secara maksimal dan lebih efektif; 4) Disarankan guru dapat mempersiapkan desain

\section{DAFTAR PUSTAKA}

Budiyono. 2003. Metodologi Penelitian Pendidikan. Surakarta: UNS Press

Departemen Pendidikan Nasional, 2006. Kurikulum 2006 SMA (KTSP) Pedoman Khusus Pengembangan Silabus dan Penilaian Mata Pelajaran Matematika. Jakarta: Departemen Pendidikan Nasional.

Isjoni. 2011. Pembelajaran Kooperatif. Yogyakarta: Pustaka Pelajar

Muniroh, K. 2010. Implementasi Pembelajaran dengan Model Cooperative Script sebagai Usaha untuk Meningkatkan Kreativitas dalam Pemecahan Masalah Matematika Siswa Kelas VIII MTs Wahid Hasyim Sleman Yogyakarta, (Online),http://eprints.uny.ac.id/1938/1 /Skripsi_Khayyizatul_Muniroh.pdf), diakses 24 Januari 2015.

Nuha, Uli. 2013. Efektivitas Pembelajaran Matematika Menggunakan Model Cooperative Script dengan Pendekatan Problem Posing terhadap Motivasi dan Hasil Belajar Matematika Siswa Kelas X di SMA Ma'arif NU 1 Kemranjen. Skripsi tidak diterbitkan. Yogyakarta: UIN Sunan kalijaga. pembelajaran ke dalam bentuk peta pikiran karena peta pikiran dapat dijadikan salah satu alternatif merangkum pelajaran, sehingga memudahkan siswa memahami dan mengingat materi pembelajaran; 5) Model pembelajaran Cooperative Script berbantuan peta pikiran dapat diterapkan dalam pembelajaran Matematika pada materi pokok yang lain yang dirasa cocok menggunakannya dan pada tingkat sekolah tertentu.

Sani, R. A. 2013. Inovasi Pembelajaran. Jakarta: Bumi aksara.

Shoimin, A. 2014. 68 Model Pembelajaran Inovasi dalam Kurikulum 2013. Yogyakarta: Ar-Ruzz Media.

Sugiyono. 2007. Statistika untuk Penelitian. Bandung: Alfabeta.

Siwi, Cahayaning Wahyu, 2004. Penerapan Model Pembelajaran Induktif pada Pokok Bahasan Reaksi Redoks di Kelas 1-4 SMA Negeri 8 Kediri. Surabaya: Fakultas Matematika dan Ilmu Pengetahuan Alam. Universitas Negeri Surabaya.

Syah, Muhibbin. 2007. Psikologi Belajar. Jakarta: PT Raja Grafindo Persada. 